\title{
Modafinil \#259
}

\author{
Jennifer Cheng, M.D. and Hunter Groninger, M.D.
}

\section{Background}

$\mathbf{M}$ ODAFINIL IS A nonamphetamine psychostimulant approved for the treatment of excessive daytime somnolence associated with obstructive sleep apnea, narcolepsy, and shift work sleep disorder. Expanding research demonstrates potential indications for modafinil in cancer and noncancer palliative care settings. This Fast Fact reviews use of modafinil for symptom management in the seriously ill.

\section{Pharmacology}

Although the exact mechanism is unclear, modafinil's action may involve enhanced catecholaminergic signaling and decreased gamma aminobutyric acid (GABA) release, primarily at the anterior hypothalamus. ${ }^{1,2}$ Rapidly absorbed after oral ingestion, the drug reaches peak plasma levels in two to four hours, with a half-life of 10 to 13 hours. It is primarily metabolized by the liver, with subsequent renal elimination of inactive metabolites. Compared to methylphenidate, modafinil has low-abuse potential and less rapid development of tolerance. $^{3}$

\section{Research Findings}

- In cancer populations: One placebo-controlled trial with a $200 \mathrm{mg}$ daily dose of modafinil resulted in significantly reduced excessive daytime sleepiness in patients with severe chemotherapy related fatigue. ${ }^{4}$ Modafinil has also been shown to be effective for specific symptoms in nonsmall cell lung cancer (fatigue, daytime drowsiness, depression); in breast cancer (fatigue); and in brain cancer (cognitive functioning, mood, and fatigue, and physical activity). 5,6,7 Finally, in advanced-stage cancer patients with Karnofsky performance status of $50 \%$ to $70 \%$, modafinil $200 \mathrm{mg}$ daily improved attention and psychomotor speed as well as subjective scores of drowsiness and depression. ${ }^{2}$
- In noncancer conditions: Generally, these smaller controlled trials have generated conflicting results. Compared to placebo, use of modafinil may reduce fatigue in patients with HIV/AIDS and amyotrophic lateral sclerosis. ${ }^{8,9}$ However, recent studies have not shown significant improvement in fatigue in patients with multiple sclerosis, Parkinson's disease, and myotonic muscular dystrophy. ${ }^{10-12}$

There are limited data comparing modafinil and methylphenidate in cancer and noncancer populations; one open-label pilot trial comparing modafinil with methylphenidate immediate release and methylphenidate sustained release in primary brain tumor patients found no significant difference in cognitive improvement between groups. ${ }^{13}$ Studies were sponsored by modafinil's manufacturer. $4,6,7,10$

\section{Dosage}

Lower doses (50-200 mg, once daily in the morning) are generally prescribed for fatigue and concentration difficulties, and higher doses (up to $600 \mathrm{mg}$ /day) are used for excessive sleepiness. ${ }^{14}$

\section{Toxicity and Precautions}

More common side effects include dose-related headaches $(34 \%)$, nausea $(11 \%)$, nervousness $(7 \%)$, and diarrhea $(6 \%)$. Hypertension rarely occurs, but monitoring of blood pressure is recommended. ${ }^{15}$

In patients with severe hepatic impairment, reduce dose by $50 \%$. Safety and efficacy have not been evaluated for patients with renal impairment. ${ }^{15}$ Use cautiously in patients with bipolar disorder or preexisting psychosis (may stimulate mania/hypomania) ${ }^{16}$ and in patients with ischemic or structural heart disease (may precipitate palpitations, tachyarrhythmia, or chest pain). ${ }^{15}$

Fast Facts and Concepts are edited by Drew A. Rosielle, M.D., Palliative Care Program, University of Minnesota Medical School and Fairview Health Services, and are published by the End of Life/Palliative Education Resource Center at the Medical College of Wisconsin. For more information write to: drosiel1@fairview.org. More information, as well as the complete set of Fast Facts, are available at EPERC: www.mcw.edu/eperc.

Copyright/Referencing Information: Users are free to download and distribute Fast Facts for educational purposes only. Available at: www.eperc.mcw.edu/fastfact/ff_259.htm.

Disclaimer: Fast Facts and Concepts provide educational information. This information is not medical advice. Health care providers should exercise their own independent clinical judgment. Some Fast Facts cite the use of a product in a dosage, for an indication, or in a manner other than that recommended in the product labeling. Accordingly, the official prescribing information should be consulted before any such product is used. 


\section{Cost}

Modafinil costs approximately $\$ 608$ for $30100 \mathrm{mg}$ tablets compared to $\$ 33$ for 30 tablets of methylphenidate $10 \mathrm{mg} .{ }^{17}$

\section{Summary}

Palliative care patients are often seriously debilitated by fatigue, excessive daytime somnolence, and depression; and modafinil may reduce these symptoms. Pending more conclusive randomized controlled trials, its use is likely limited by cost and availability. Nonetheless, even now modafinil may have a therapeutic niche when methylphenidate use is contraindicated or limited due to side effects.

\section{References}

1. Lin J-S, Hou Y, Jouvet M: Potential brain neural targets for amphetamine-, methylphenidate-, and modafinil-induced wakefulness, evidenced by c-fos immunochemistry in the cat. Proc Natl Acad Sci USA 1996;93:14128-14133.

2. Ludorff LE, Jonsson BH, Sjogren P: Modafinil for attentional and psychomotor dysfunction in advanced cancer: A double-blind, randomized, cross-over trial. Palliat Med 2009; 23(8):731-738.

3. Webster L, Andrews M, Stoddard G: Modafinil treatment of opioid-induced sedation. Pain Med 2003;4:135-140.

4. Jean-Pierre P, Morrow GR, Roscoe JA: A phase 3 randomized, placebo-controlled, double-blind, clinical trial of the effect of modafinil on cancer-related fatigue among 631 patients receiving chemotherapy. Cancer 2010;116:3513-3520.

5. Spathis A, Dhillan R, Booden D, et al.: Modafinil for the treatment of fatigue in lung cancer: A pilot study. Palliat Med 2009;23:325-331.

6. Morrow GR, Gillies LJ, Hickok JT, et al.: The positive effect of the psychostimulant modafinil on fatigue from cancer that persists after treatment is completed. J Clin Oncol 2005; 3(Suppl):8012.

7. Kaleita TA, Wellisch DK, Graham CA, et al.: Pilot study of modafinil for treatment of neurobehavioral dysfunction and fatigue in adult patients with brain tumors. J Clin Oncol 2006;24(Suppl):1503.

DOI: $10.1089 / j p m .2012 .9543$
8. Rabkin JG, McElhiney MC, Rabkin R, McGrath P: Modafinil treatment for fatigue in patients with HIV / AIDS: A placebo controlled study. J Clin Psych 2010;71(6):707-715.

9. Rabkin JG, Gordon PH, McElhiney M, et al.: Modafinil treatment of fagitue in patients with ALS: A placebocontrolled study. Muscle Nerve 2009;39:297-303.

10. Moller F, Poettgen J, Broemel F, et al.: HAGIL (Hamburg Vigil Study): A randomized placebo-controlled double-blind study with modafinil for treatment of fatigue in patients with multiple sclerosis. Mult Scler 2011;17:1002-1009.

11. Seppi K, Weintraub D, Coelho M, et al.: The Movement Disorders Society evidence-based medicine review update: Treatments for the non-motor symptoms of Parkinson's disease. Movement Disorders 2011;26(S3):42-80.

12. Orlikowski D, Chevret S, Quera-Salva MA, et al.: Modafinil for the treatment of hypersomnia associated with myotonic muscular dystrophy in adults: A multicenter, prospective, randomized, double-blind, placebo-controlled, 4-week trial. Clin Therap 2009;31(8):1765-1773.

13. Gehring K, Patwardhan SY, Collins R, et al.: A randomized trial on the efficacy of methylphenidate and modafinil for improving cognitive functioning and symptoms in patients with a primary brain tumor. J Neurooncol 2012;107(1):165-167.

14. Harris JD: Fatigue in chronically ill patients. Curr Opin Supp Pall Care 2008;2:180-186.

15. Thomson Reuters (Healthcare) Inc.: Modafinil: Drug information. In: PDR Electronic Library. ${ }^{\mathrm{TM}}$ www.thomsonhc.com. (Last accessed May 10, 2012.)

16. Wingo AP, Ghaemi SN: Frequency of stimulant treatment and of stimulant-associated mania/hypomania in bipolar disorder patients. Psychopharmacol Bull 2008;41(4):37-47.

17. Drugstore.com Online Pharmacy: drugstore.com. (Last accessed: March 15, 2012.)

Address correspondence to: Hunter Groninger, M.D. Pain and Palliative Care Service Clinical Center, Room 2-1733

National Institutes of Health

Bethesda, MD 20829

E-mail: hunter.groninger@nih.gov

\title{
Opoid Use in Liver Failure \#260
}

\author{
Carlene Oliverio, PharmD, BCPS, Natalie Malone, PharmD, and Drew A. Rosielle, M.D.
}

\section{Background}

$\mathbf{M}$ OST OPIOIDS ARE at least partially metabolized by the liver, complicating their use in liver failure. This Fast Fact discusses the use of opioids in patients with liver failure (see also Fast Facts \#161 about opioid use in renal failure, \#176 and \#177 about managing ascites, and \#189 about prognostication in end-stage liver disease: www.mcw.edu/ eperc). While there are plenty of pharmacokinetic data about opioids and liver failure, all the clinical recommendations below are rational and empiric, but not based on clinical outcomes research. 